\title{
Control of Lower Extremity Edema in Patients with Diabetes: Double Blind Randomized Controlled Trial Assessing the Efficacy of Mild Compression Diabetic Socks
}

\author{
Stephanie C. Wu, DPM, MSc, FACFAS ${ }^{\star}$, Ryan T. Crews, MS ${ }^{\star}$, Melissa Skratsky, DPM ${ }^{\star}$, Julia \\ Overstreet, DPM ${ }^{\ni}$, Sai V. Yalla, PhD $^{\star}$, Michelle Winder, BS $^{*}$, Jacquelyn Ortiz, CCRP*, and \\ Charles A. Andersen, MD ${ }^{\ni}$ \\ ${ }^{*}$ Center for Lower Extremity Ambulatory Research (CLEAR), Dr. William M. Scholl College of \\ Podiatric Medicine at Rosalind Franklin University of Medicine and Science, North Chicago, IL \\ ${ }^{\ni}$ Madigan Army Medical Center, Tacoma, WA
}

\begin{abstract}
Aims-Persons with diabetes frequently present with lower extremity (LE) edema; however, compression therapy is generally avoided for fear of compromising arterial circulation in a population with a high prevalence of peripheral arterial disease. This double blind randomized controlled trial (RCT) assessed whether diabetic socks with mild compression could reduce LE edema in patients with diabetes without negatively impacting vascularity.
\end{abstract}

\begin{abstract}
Methods-Eighty subjects with LE edema and diabetes were randomized to receive either mildcompression knee high diabetic socks $(18-25 \mathrm{mmHg})$ or non-compression knee high diabetic socks. Subjects were instructed to wear the socks during all waking hours. Follow-up visits occurred weekly for four consecutive weeks. Edema was quantified through midfoot, ankle, and calf circumferences and cutaneous fluid measurements. Vascular status was tracked via ankle brachial index (ABI), toe brachial index (TBI), and skin perfusion pressure (SPP).
\end{abstract}

Results-Seventy-seven subjects (39 controls and 38 mild-compression subjects) successfully completed the study. No statistical differences between the two groups in terms of age, body mass index, gender, and ethnicity.

\footnotetext{
Corresponding Author: Stephanie C. Wu, DPM, MSc, FACFAS, CLEAR, Dr. William M. Scholl College of Podiatric Medicine at Rosalind Franklin University of Medicine and Science, 3333 Green Bay Rd., North Chicago, IL 60064, (p) 847-578-8420, (f) 847-775-6570, Stephanie.Wu@ rosalindfranklin.edu.

Publisher's Disclaimer: This is a PDF file of an unedited manuscript that has been accepted for publication. As a service to our customers we are providing this early version of the manuscript. The manuscript will undergo copyediting, typesetting, and review of the resulting proof before it is published in its final citable form. Please note that during the production process errors may be discovered which could affect the content, and all legal disclaimers that apply to the journal pertain.

Conflicts of Interests:

The authors have no conflicts of interest to report relative to this manuscript.

Author Contributions:

SWC designed the study, conducted data collection, analyzed data and drafted the manuscript. RTC designed the study, conducted data collection, analyzed data and drafted the manuscript. MS conducted data collection, analyzed data and reviewed the manuscript. JO conducted data collection and reviewed the manuscript. SVY conducted data collection and reviewed the manuscript. MW conducted data collection, data analyses and reviewed the manuscript. JO collected data, analyzed data and reviewed the manuscript. CAA designed the study, collected data and reviewed the manuscript.

Manuscript Guarantor: Stephanie C. Wu
} 
Repeated measures analysis of variance and Sidak corrections for multiple comparisons were used for data analyses. Subjects randomized to mild-compression diabetic socks demonstrated significant decreases in calf and ankle circumferences at the end of treatment as compared to baseline. LE circulation did not diminish throughout the study with no significant decreases in ABI, TBI or SPP for either group.

Conclusions-Results of this RCT suggest that mild compression diabetic sock may be effectively and safely used in patients with diabetes and LE edema.

\section{Keywords}

Lower extremity; edema; swelling; mild compression; diabetes; sock

\section{Introduction}

Lower extremity edema is often an early sign of significant fluid retention that could result in cardiac overload and conditions such as heart failure and is a common clinical finding in persons with diabetes [1-3]. Persons with type 2 diabetes mellitus especially, have a higher prevalence of peripheral edema than healthy subjects $[4,5]$. However, the lack of reliable measures to objectively quantify peripheral edema makes it difficult to assess the true prevalence in this population [6]. In a prospective study of 314 patients with diabetic foot ulcers, $38 \%$ presented with lower extremity edema [7]. The presence of lower extremity edema was an indicator of poorer prognosis as peripheral edema presented more commonly in patients who required amputation (58\%) or died (55\%). The cause of edema may be difficult to isolate and may be secondary to multiple etiologies. Diabetes is a strong and independent risk factor for congestive heart failure, and is the leading cause of kidney failure. Peripheral edema is found with both of these conditions. In addition to systemic cardiovascular and renal disease, several other factors may contribute to peripheral edema in the diabetic patient. The use of certain antihyperglycemic medications, especially in combination with insulin, is associated with an increased incidence of edema [5]. Both pioglitazone and rosiglitazone from the thiazolidinedione class of medications have been associated with increased development of lower leg edema in clinical trials. The incidence of edema in these trials varied from approximately 3.0 to $7.5 \%$ with the thiazolidinediones compared with 1.0 to $2.5 \%$ with placebo or other oral antihyperglycemic therapy. The highest incidence of edema was reported when thiazolidinediones were used in combination with insulin. In clinical studies, patients had a $15.3 \%$ incidence of edema when treated with insulin plus pioglitazone and $14.7 \%$ when treated with insulin plus rosiglitazone, compared with $7.0 \%$ and $5.4 \%$ in the insulin-only groups, respectively. This edema was partly attributed to the 6-8\% increase in plasma volume associated with use of these drugs [8,9].

Multiple medications commonly used in the diabetic treatment plan including calcium channel blockers, vasodilator angiotensins, non-steroidal anti-inflammatory drugs, and some medications used to manage neuropathic pain have adverse profiles that include peripheral edema $[10,11]$. Of the calcium channel blockers, dihydropyridines are more likely to induce peripheral edema than are the phenylalkylamine or benzothiazepine classes, purportedly because of more selective arteriolar vasodilatation. 
Prior to treating lower extremity edema, a thorough history and physical must be performed to address the underlying pathology. Once systemic pathology has been managed or ruled out, peripheral edema is most often treated with graduated compression therapy [12-14]. However, patients with diabetes have a 2-5 times greater risk for developing peripheral arterial disease (PAD) [15-17] as compared to those without diabetes, and compression therapy has long been considered risky practice in patients with diabetes because of the fear of compromising vascularity $[18,19]$. As a result, foot elevation as opposed to graduated compression has generally been recommended to reduce lower extremity edema, and the diabetic socks currently advocated by healthcare professionals offer either no compression or minimal compression, no greater than $8-15 \mathrm{mmHg}$, to preemptively guard against exacerbating symptoms of lower extremity PAD. In ambulatory individuals, the best outcomes from foot elevation would be cyclic periods of swelling and subsequent reduction. Moreover, foot elevation may decrease pedal tissue oxygenation since the dependent position is known to increase blood flow within the arterial system [20]. Although many physicians are aware of the importance of monitoring and treating peripheral edema, accuracy of assessment and consistency in treatment has been a challenge. A four-week open label pilot study involving 20 subjects with diabetes and lower extremity edema suggested diabetic socks designed to provide mild compression (18-25mmHg) (Sigvaris Inc., Peachtree City, GA) can be used to decrease lower leg edema without compromising vascular flow [21]. The primary objective of this five week, multi-center, double blind randomized controlled trial was to assess the effectiveness of a diabetic sock that provides mild compression (18-25mmHg) as compared to a non-compression diabetic sock in patients with both diabetes and lower extremity edema. The secondary objective was to assess the effect of the mild compression diabetic sock versus the non-compression diabetic sock on lower extremity macro and microcirculation. This study was registered with ClinicalTrials.gov and assigned the Identifier: NCT01529385.

\section{Material and Methods}

\subsection{Study Sample}

This double blind randomized controlled trial enrolled 80 outpatient participants from two sites, Rosalind Franklin University Health System (50) in North Chicago, Illinois, and the Madigan Army Medical Center (30) in Tacoma, Washington. The study received ethical approval from the local institutional review boards (IRB). All participants received oral and written information and signed an IRB approved informed consent before participating. Participants were recruited between February, 2012 and August, 2014. Data collection concluded in September, 2014.

Male or female patients aged 18 years or older with diabetes, clinically diagnosed mild/ moderate lower extremity edema, an ankle-brachial systolic pressure index $\geq 0.6$ and toebrachial index $\geq 0.3$ were included for the study [22, 23]. Patients with an active wound infection, untreated osteomyelitis, gangrene, wide spread malignancy, systemically immunocompromising disease, restless leg syndrome, Parkinson's disease, or any other disease that can cause involuntary movement during microvascular assessment were excluded from the study. Patients with deep and/or large ulcers that required copious bandaging that would 
have prohibited the donning of study socks were also excluded from the study. Patients who were currently (anytime within previous 6 months) wearing prescription compression hose, or had severe edema/lymphedema with calf circumference greater than $46 \mathrm{~cm}$ (24in) that in the opinion of the investigator would require higher compression than the $18-25 \mathrm{mmHg}$ provided by the compression socks were also excluded from the study.

Sample size calculations were made using data from the previous pilot study [21]. Utilizing observed changes in calf circumference with a power of $80 \%$ and alpha of 0.0555 patients would have been required to show a decrease in calf circumference. In order to account for up to a $30 \%$ fall out rate a total of 80 subjects were recruited. Based upon participants' feedback from the initial pilot study investigating these compression socks, we had reason to believe the compression socks might induce a change in physical activity. Thus physical activity was studied in a sub-sample within the present study; however, delving into this secondary investigation is beyond the intended scope of the present publication. Therefore, the authors plan to have a secondary publication focusing on the physical activity implications of the compression socks.

\subsection{Randomization}

Subjects were randomized to one of the two treatment groups: (1) mild compression knee high diabetic socks that provided $18-25 \mathrm{mmHg}$ of pressure, (2) non-compression knee high diabetic socks. Randomization was done in a 1:1 ratio using a computer generated sequentially assigned block randomization plan.

\subsection{Patient events after entry}

2.3.1 Screening/Baseline-Subjects were screened to ensure that they met the inclusion and exclusion criteria. A detailed medical and compression history and standardized physical exam, including vascular, dermatological, and neurological were conducted as part of a regular care visit. Diabetic peripheral neuropathy was defined as inability to accurately perceive a 10g Semmes-Weinstein monofilament at 1 or more of 10 test sites on the sole and dorsum of the foot [24].

2.3.2 Lower Extremity Edema Assessment-Lower extremity edema assessment consisted of four measurements: foot circumference (taken at the widest portion of the midfoot area), ankle circumference (taken as narrowest portion of ankle region), and calf circumference (taken at the widest portion of the calf) by the same clinician [6].

Circumference measurements were verified by taking the widest of three measurements of the widest portion of the calf and midfoot, and by taking the narrowest of three measurements of the ankle. A spring-loaded Gulick tape measure was used for girth measurements. The Gulick tape measure is a compact, self-locking device with flexible vinyl tape that will not stretch and a push-button release. It is spring-loaded to offer a high level of accuracy with consistent tension that prevents excessive compression of body tissue. The leg with the highest girth measurements was designated the study leg for the remainder of the study. Patients' cutaneous edema or local skin tissue water was measured via dielectric constant (MoistureMeter-D, Delfin Technologies, Ltd., Kuopio, Finland) [25]. The probe for measuring the tissue dielectric constant was placed at a single location; two inches 
distal and two inches lateral to the fibular head. The probe was held in contact with the skin using gentle pressure. Each time the tissue dielectric constant was assessed, four measurements were obtained and the averaged value was recorded as the outcome measure.

2.3.3 Vascular Assessment-Ankle brachial pressure indices (ABI) and toe brachial indices (TBI) were performed bilaterally (PadNet, BioMedix, St. Paul, MN) after the subject had been resting in the supine position for five minutes. Skin perfusion pressure (SPP) as measured by laser doppler was also obtained to assess microvascular circulation [26-28]. The angiosome principle, defined by Ian Taylor in his landmark anatomic study in 1987, divides the body into three-dimensional anatomic units of tissue supplied by specific source arteries [29, 30]. SPP of the Tibialis Anterior angiosome (anterior lateral calf), Tibialis Posterior angiosome (medial calf) and Dorsalis Pedis portion of Tibialis Anterior Angiosome (proximal $1^{\text {st }}$ interspace) were measured (SensiLase, Väsamed, Eden Prairie, MN). SPP data was reviewed by four blinded investigators (SCW, RTC, MW, JO) as well as by experts from the manufacturer to ensure correctness.

\subsection{Intervention}

Following randomization each subject was dispensed either four pairs of the mild compression diabetic socks or the non-compression diabetic socks manufactured by the same company for purposes of blinding. The socks were fitted according to manufacturer's instructions. Subjects were advised to wear the socks at all times while awake and return to clinic at one-week intervals for 4 weeks. Written and oral instructions for application and care (washing and maintenance) of socks were provided to each subject.

\subsection{Follow-up Visits}

At each follow-up visit the following procedures were repeated: measurement of foot, ankle and calf circumferences; dielectric constant measurements performed in triplicates, ABI and TBI measurement; measurement of SPP of lateral calf, medial calf and dorsal proximal $1^{\text {st }}$ interspace of foot. Additionally, the subjects' completed a survey regarding sock usage and comfort. The survey asked subjects what proportion of waking hours they wore their socks $(0,25,50,75$ or $100 \%)$ and provided five options for them to rate the comfort of the socks (see Table 3).

\subsection{Statistical analyses}

Demographic data was compared between the two groups to ensure homogeneity of the two groups, with continuous variables compared via independent t-tests and categorical variables compared via chi-square tests. Outcomes variables were compared with repeated measures analysis of variance tests that included main effects of: group, visit number, and site. Sidak corrections for multiple comparisons were used for post hoc analyses when the repeated measures analysis of variance tests yielded significant findings. Survey responses were compared between the groups via chi-square tests. 


\section{Results}

Seventy-seven subjects successfully completed the study (Figure 1). Thirty-nine subjects were randomized to the control arm and 38 to the treatment arm. Patient characteristics are summarized in Table 1. There were no statistically significant differences between the two groups in terms of age, gender, body mass index, and ethnicity. There was also no statistical significance between the two groups in terms of risk factors for cardiovascular disease including hypertension, hypercholesterolemia, and obesity. Similarly, there were no between group differences in medications taken for diabetes and hypertension control (Table 1).

The main effects of group and visit number were not found to be significant for any of the outcome measures. The main effect of site was found to be significant for some of the vascular measures. ABI values were significantly $(\mathrm{p}=.000)$ higher at the North Chicago site than the Tacoma site (mean difference $=.264 ; 95 \% \mathrm{CI}=.211$ to .316 ). TBI was also higher $(\mathrm{p}=.005)$ at the Chicago site (mean difference $=.106 ; 95 \% \mathrm{CI}=.034$ to .178$)$. In contrast, medial calf skin perfusion pressure values were higher $(\mathrm{p}=.001)$ at the Tacoma site (mean difference $=6.77 \mathrm{mmHg} ; 95 \% \mathrm{CI}=2.75$ to 10.80 ). Results regarding the interaction of study visit within group are presented in Table 2 and significant changes from baseline are highlighted (Sidak correction for multiple comparisons used). There was no difference between groups in regards of sock usage (Table 3$)$. However, there was a difference $(\mathrm{p}<.01)$ in comfort ratings of the socks after the first week of sock usage, with the control group having more ratings of "very comfortable" (Table 3). After four weeks of usage, there was no between group difference and the majority of subjects in both groups rated their socks as "very comfortable." The adverse events for this study are summarized in Table 4.

\section{Discussion}

There are currently hundreds of diabetic socks available on the market. Diabetic socks tend to be very soft and stretchy, have a seamless toe design, are cushioned, and have a comfortable top band. However, they generally offer minimal to no compression and are not ideal for patients with diabetes and concomitant lower extremity edema. The effectiveness of compression therapy in reducing leg edema has been known for decades and confirmed in numerous studies [31]. Exerting carefully controlled pressure on the leg tissue and blood vessels supports the calf muscle pump and improves venous valve function. In turn, this speeds up the flow of blood from the legs back to the heart. The disadvantage of regular compression stockings is that they do not cater for the specific needs of diabetic feet. This means that they may contain fine but nevertheless irritating seams. The stocking fabric is not as soft and there is no padding. What's more, compression is exerted on the foot. These are all factors that make it impossible for diabetic patients to use regular compression stockings in many instances. As such, leg edema among individuals with diabetes often remain untreated and can lead to associated complications long term [32].

Subjects randomized to mild compression diabetic socks demonstrated a significant decrease in calf and ankle circumferences at the end of treatment as compared to baseline. Lower extremity circulation was maintained in both groups throughout the study with no significant change in ABI, TBI, or SPP for either group. The findings of this double blind RCT 
correlates well with the results of the pilot study as well as with other studies that assessed the effects of mild compression in patients with concomitant lower extremity edema secondary to venous insufficiency and PAD. Compression therapy has been used successfully in patients with ABI as low as 0.5, and supervised reduced compression of 15$25 \mathrm{mmHg}$ has been advised for patients with an ABI between 0.5-0.85 [33, 34].

A decreasing trend in foot circumference was noted in subjects randomized to mild compression diabetic socks, however, unlike the decreases in calf and ankle circumferences at the end of treatment, the decrease in foot circumference was not statistically significant. This finding is consistent with the construct of the diabetic mild compression socks where the compression starts from the ankle area and extends proximally to just below the knee. The foot portion of the sock offers little to no compression. This finding also highlights the significant effect of mild compression on lower extremity edema and correlates well with the findings of a meta-analysis, where mild compression of $10-20 \mathrm{mmHg}$ was found to have a clear effect on lower extremity edema and symptoms as compared with placebo stockings, no treatment, or stockings with $<10 \mathrm{mmHg}$ of pressure [35].

The tissue dielectric constant (TDC) measures the permittivity of tissue and is an index of local skin tissue water $[36,37]$. Prior research suggests that TDC values are useful to assess localized skin water for changes secondary to edema $[25,38]$. In contrast to findings from the pilot study and other edema studies [39] where decreases in girth positively correlated with decreases in TDC, our study found no significant changes in TDC for either group. Other studies that demonstrated significant decreases in TDC utilized pressures of $30 \mathrm{mmHg}$ and higher $[25,38,39]$ and one can stand to reason that the $18-25 \mathrm{mmHg}$ of pressure provided by the mild compression socks may simply not be high enough to produce a significant measurable difference in the skin water content in one specific isolated area. TDC measurements reflect local tissue water changes to a depth of $5 \mathrm{~mm}$ whereas girth or circumference measurements reflect conditions of the entire cross-section [38, 39]. While $18-25 \mathrm{mmHg}$ of compression may not be high enough to result in a significant decrease in the local skin water content, it did significantly reduce the overall edema of the entire crosssection of the calf and ankle.

LE circulation was maintained in both groups throughout the study with no significant change in ABI, TBI, or SPP for either group. Our finding suggests that mild compression therapy does not affect arterial blood supply and is consistent with that of other studies where compression in patients with mixed etiology leg ulcers did not have a statistically significant effect on digital blood pressure measurements when compared with no compression [40, 41].

One interesting finding was noted from patient surveys. In general, subjects reported compliance to wearing the socks primarily because they felt comfortable wearing the socks [42]. As indicated in Table 3, after the first week of usage significantly more control subjects reported their socks as being "very comfortable than did compression subjects $(92 \%(36 / 39)$ VS. 53\% (19/36)). However by week 4 there was no group difference and the majority of both groups ( $89 \%$ vs. $81 \%$ ) felt their socks were very comfortable. Patient comfort has a direct correlation with compliance to compression therapy [43]. The comfort findings of the 
present study suggest that the mild compression diabetic stocking is well tolerated in patients with diabetes and lower extremity edema and correlates well with other reports that low pressure, knee length compression stockings provide the most patient comfort [44, 45].

Four adverse events (AEs) occurred in the compression group and six in the control group. One of the compression group AEs was deemed as definitely related to the compression socks. The adverse event was skin irritation at the proximal-medial aspect of the left leg. Two AEs consisting of lower extremity muscle cramping occurred in the same compression group subject were deemed as probably related to the intervention. The final AE in the compression group was irritation of the skin on the dorsum of the $4^{\text {th }}$ digit that was deemed possibly related to the intervention. Five of the control group AEs were considered not related to the study device. Within the control group, one incident of pain and numbness radiating from the hips was deemed as possibly related to the study device. One serious adverse event (SAE) occurred in the compression group and two SAEs occurred in the control group. None of the SAEs was deemed to be related to the study.

Limitations to this study included the inability to provide education about diet and life style control for lower extremity edema to either group. While various factors such as diet and salt intake may have some effects on lower extremity edema, we feel that the four-week duration of the study is a relative short time for significant changes in weight and diet regimens for the majority of the ambulatory, non-institutionalized population. Furthermore, the randomized controlled trial design limits the likelihood of weight and diet changes having any meaningful impact on the study results. Other limitations of the study include the inability to ensure patient compliance to wearing the socks, human imprecision with girth measurements, and inability to have all patients assessed at the same time of day.

In conclusion subjects randomized to mild compression socks demonstrated significant decrease in LE edema and control subjects had no change. Macro and microvascularity was not compromised in either group. Results of this study suggest that mild compression diabetic sock may be effectively and safely used in patients with diabetes and LE edema.

\section{Acknowledgments}

The study was funded by a grant from Sigvaris Inc. (Peachtree City, GA) the manufacturer of the mild-compression socks. The sponsor played no role in the conduct of the study, the analysis of the data, nor the conclusions drawn from the data.

The study was also partially supported by grant number 2T35DK074390 from the National Institute of Diabetes and Digestive and Kidney Disease. The content is solely the responsibility of the authors and does not represent the official views of the National Institute of Diabetes and Digestive and Kidney Diseases of the National Institutes of Health Results from the study were previously published in abstract form in: Diabetes, June 2015, 64(S1): A37. doi: $10.2337 / \mathrm{db} 15-1-385$

\section{References}

1. Eberth-Willershausen W, Marshall M. Prevalence, risk factors and complications of peripheral venous diseases in the Munich population. Hautarzt. 1984; 35:68-77. [PubMed: 6608508]

2. Yu GV, Schubert EK, Khoury WE. The Jones compression bandage. Review and clinical applications. Journal of the American Podiatric Medical Association. 2002; 92:221-31. [PubMed: 11961089] 
3. Chantelau E. Symptom veiled by polyneuropathy. Swollen foot in diabetes mellitus. MMW Fortschritte der Medizin. 2006; 148:46-7.

4. Messerli FH. Vasodilatory edema: a common side effect of antihypertensive therapy. American journal of hypertension. 2001; 14:978-9. [PubMed: 11587169]

5. Mudaliar S, Chang AR, Henry RR. Thiazolidinediones, peripheral edema, and type 2 diabetes: incidence, pathophysiology, and clinical implications. Endocrine practice: official journal of the American College of Endocrinology and the American Association of Clinical Endocrinologists. 2003; 9:406-16.

6. Brodovicz KG, McNaughton K, Uemura N, Meininger G, Girman CJ, Yale SH. Reliability and feasibility of methods to quantitatively assess peripheral edema. Clin Med Res. 2009; 7:21-31. [PubMed: 19251582]

7. Apelqvist J, Larsson J, Agardh CD. The importance of peripheral pulses, peripheral oedema and local pain for the outcome of diabetic foot ulcers. Diabet Med. 1990; 7:590-4. [PubMed: 2146065]

8. Thomas ML, Lloyd SJ. Pulmonary edema associated with rosiglitazone and troglitazone. Ann Pharmacother. 2001; 35:123-4. [PubMed: 11197573]

9. Gorson DM. Significant weight gain with rezulin therapy. Arch Intern Med. 1999; 159:99.

10. Cho S, Atwood JE. Peripheral edema. Am J Med. 2002; 113:580-6. [PubMed: 12459405]

11. Andresdottir MB, van Hamersvelt HW, van Helden MJ, van de Bosch WJ, Valk IM, Huysmans FT. Ankle edema formation during treatment with the calcium channel blockers lacidipine and amlodipine: a single-centre study. J Cardiovasc Pharmacol. 2000; 35:S25-30.

12. Armstrong DG, Nguyen HC. Improvement in healing with aggressive edema reduction after debridement of foot infection in persons with diabetes. Arch Surg. 2000; 135:1405-9. [PubMed: 11115342]

13. Gardner, AMN., Fox, RH. The return of blood to the heart: venous pumps in health and disease. London: John Libbey; 1989.

14. Gaskell P, Parrott JCW. The effect of a mechanical venous pump on the circulation of the feet in the presence of arterial obstruction. Surg Gyn Obst. 1978; 146:583-92.

15. Akbari CM, LoGerfo FW. Diabetes and peripheral vascular disease. J Vasc Surg. 1999; 30:373-84. [PubMed: 10436463]

16. Banga JD. Lower extremity arterial disease in diabetes mellitus. Diab Rev Int. 1994; 3:6-11.

17. Dinh T, Scovell S, Veves A. Review: peripheral arterial disease and diabetes: a clinical update. The international journal of lower extremity wounds. 2009; 8:75-81. [PubMed: 19443896]

18. Eneroth M, Persson BM. Amputation for occlusive arterial disease, a propsective multicenter study of 177 amputees. Int Orthop. 1992; 16:383-7. [PubMed: 1473894]

19. Pawlaczyk K, Gabriel M, Urbanek T, Dzieciuchowicz L, Krasinski Z, Gabriel Z, et al. Effects of Intermittent Pneumatic Compression on Reduction of Postoperative Lower Extremity Edema and Normalization of Foot Microcirculation Flow in Patients Undergoing Arterial Revascularization. Med Sci Monit. 2015; 21:3986-92. [PubMed: 26690828]

20. Park DJ, Han SK, Kim WK. Is the foot elevation the optimal position for wound healing of a diabetic foot? Journal of plastic, reconstructive \& aesthetic surgery: JPRAS. 2010; 63:561-4.

21. Wu SC, Crews RT, Najafi B, Slone-Rivera N, Minder JL, Andersen CA. Safety and efficacy of mild compression (18-25 mm Hg) therapy in patients with diabetes and lower extremity edema. $\mathrm{J}$ Diabetes Sci Technol. 2012; 6:641-7. [PubMed: 22768895]

22. Khan TH, Farooqui FA, Niazi K. Critical review of the ankle brachial index. Current cardiology reviews. 2008; 4:101-6. [PubMed: 19936284]

23. Santilli JD, Santilli SM. Chronic critical limb ischemia: diagnosis, treatment and prognosis. American family physician. 1999; 59:1899-908. [PubMed: 10208708]

24. Armstrong DG, Lavery LA, Vela SA, Quebedeaux TL, Fleischli JG. Choosing a Practical Screening Instrument to Identify Patients at Risk for Diabetic Foot Ulceration. Archives of Internal Medicine. 1998; 158:289-92. [PubMed: 9472210]

25. Mayrovitz HN, McClymont A, Pandya N. Skin tissue water assessed via tissue dielectric constant measurements in persons with and without diabetes mellitus. Diabetes Technol Ther. 2013; 15:60 5. [PubMed: 23145992] 
26. Kato H, Watanabe S, Morita A. Skin perfusion pressure is useful for evaluating digital ulcer caused by systemic sclerosis. The Journal of dermatology.

27. Nielsen SL, Nielsen AL, Vind SH, Thomassen A. Skin perfusion pressure measured with a photo sensor in an air-filled plastic balloon: validity and reproducibility on the lower leg in normal subjects and patients suspected of obliterative arterial disease. Physiological measurement. 32:1605-10.

28. Terashi H, Iwayama T, Iida O, Kitano I, Tsuji Y. Dynamic skin perfusion pressure: a new measure of assessment for wound healing capacity and alternative angiosome in critical limb ischemia. Plastic and reconstructive surgery. 126:215e-8e.

29. Taylor GI, Palmer JH. The vascular territories (angiosomes) of the body: experimental study and clinical applications. Br J Plast Surg. 1987; 40:113-41. [PubMed: 3567445]

30. Attinger CE, Evans KK, Bulan E, Blume P, Cooper P. Angiosomes of the foot and ankle and clinical implications for limb salvage: reconstruction, incisions, and revascularization. Plast Reconstr Surg. 2006; 117:261S-93S. [PubMed: 16799395]

31. Trayes KP, Studdiford JS, Pickle S, Tully AS. Edema: diagnosis and management. Am Fam Physician. 2013; 88:102-10. [PubMed: 23939641]

32. Hunter M. Assessing the effect of chronic oedema with associated ulceration. Br J Community Nurs. 2015:S10-3. Suppl Chronic:S8. [PubMed: 26052989]

33. Humphreys ML, Stewart AH, Gohel MS, Taylor M, Whyman MR, Poskitt KR. Management of mixed arterial and venous leg ulcers. Br J Surg. 2007; 94:1104-7. [PubMed: 17497654]

34. Bowering CK. Use of layered compression bandages in diabetic patients. Experience in patients with lower leg ulceration, peripheral edema, and features of venous and arterial disease. Adv Wound Care. 1998; 11:129-35. [PubMed: 9729944]

35. Amsler F, Blattler W. Compression therapy for occupational leg symptoms and chronic venous disorders - a meta-analysis of randomised controlled trials. Eur J Vasc Endovasc Surg. 2008; 35:366-72. [PubMed: 18063393]

36. Nuutinen J, Ikaheimo R, Lahtinen T. Validation of a new dielectric device to assess changes of tissue water in skin and subcutaneous fat. Physiol Meas. 2004; 25:447-54. [PubMed: 15132310]

37. Aimoto A, Matsumoto T. Noninvasive method for measuring the electrical properties of deep tissues using an open-ended coaxial probe. Med Eng Phys. 1996; 18:641-6. [PubMed: 8953556]

38. Mayrovitz HN, Davey S, Shapiro E. Localized tissue water changes accompanying one manual lymphatic drainage (MLD) therapy session assessed by changes in tissue dielectric constant inpatients with lower extremity lymphedema. Lymphology. 2008; 41:87-92. [PubMed: 18720916]

39. Fife CE, Davey S, Maus EA, Guilliod R, Mayrovitz HN. A randomized controlled trial comparing two types of pneumatic compression for breast cancer-related lymphedema treatment in the home. Supportive care in cancer: official journal of the Multinational Association of Supportive Care in Cancer. 2012; 20:3279-86. [PubMed: 22549506]

40. Top S, Arveschoug AK, Fogh K. Do short-stretch bandages affect distal blood pressure in patients with mixed aetiology leg ulcers? J Wound Care. 2009; 18:439-42. [PubMed: 19816384]

41. Midttun M, Ahmadzay NF, Henriksen JH. Does comprilan bandage have any influence on peripheral perfusion in patients with oedema? Clinical physiology and functional imaging. 2010; 30:323-7. [PubMed: 20545712]

42. Munter C. Effect of a new compression garment on adherence: results of a patient satisfaction survey. Br J Nurs. 2015; 24(Suppl 20):S44-9.

43. Bouman AC, Ten Cate-Hoek AJ, Dirksen CD, Joore MA. Eliciting patients' preferences for elastic compression stocking therapy after deep vein thrombosis: potential for improving compliance. Journal of thrombosis and haemostasis: JTH. 2016; 14:510-7. [PubMed: 26670129]

44. Carpentier PH, Becker F, Thiney G, Poensin D, Satger B. Acceptability and practicability of elastic compression stockings in the elderly: a randomized controlled evaluation. Phlebology/Venous Forum of the Royal Society of Medicine. 2011; 26:107-13.

45. Sajid MS. Low-pressure, knee-length compression stockings provide most comfort with no effect on thrombosis risk. Evidence-based nursing. 2015 


\section{Research Highlights}

Mild compression may be effectively and safely used in diabetes patients with LE edema

Mild-compression diabetic socks significantly decreased calf and ankle circumferences

Lower extremity circulation well maintained throughout the study 


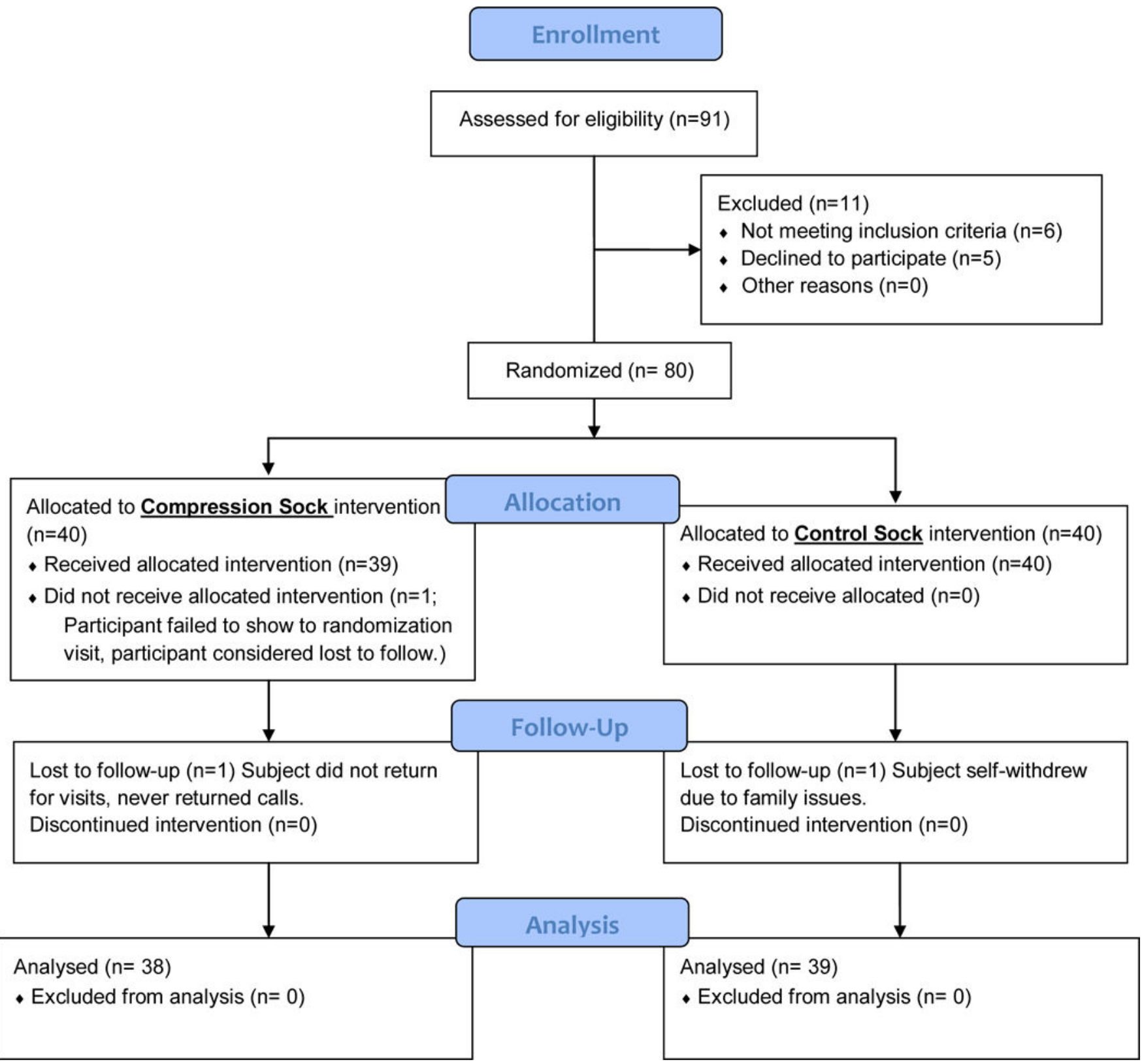

Figure 1.

Consort Flow Diagram. 
Table 1

Subject Demographics

\begin{tabular}{|c|c|c|c|c|}
\hline & & $\begin{array}{l}\text { Control } \\
\mathbf{N}=39\end{array}$ & $\begin{array}{c}\text { Compression } \\
\mathbf{N}=\mathbf{3 8}\end{array}$ & p-value \\
\hline \multicolumn{2}{|r|}{ Age (years) } & $64 \pm 13$ & $66 \pm 13$ & 0.39 \\
\hline \multicolumn{2}{|r|}{ BMI (kg/m2) } & $35.6 \pm 7.4$ & $34.3 \pm 6.3$ & 0.43 \\
\hline \multicolumn{2}{|r|}{ Weight (kg) } & 100.2 & 100.6 & 0.92 \\
\hline \multicolumn{2}{|r|}{ Hypertension } & 32 & 33 & 0.59 \\
\hline \multicolumn{2}{|r|}{ Hypercholesterolemia } & 24 & 24 & 0.89 \\
\hline \multirow{2}{*}{ Sex } & Male & 20 & 20 & \multirow{2}{*}{0.91} \\
\hline & Female & 19 & 18 & \\
\hline \multirow{5}{*}{ Race } & African American & 10 & 15 & \multirow{4}{*}{0.36} \\
\hline & Asian & 2 & 3 & \\
\hline & Native American & 1 & 0 & \\
\hline & Caucasian & 26 & 19 & \\
\hline & Not given & 0 & 1 & \\
\hline \multirow[t]{5}{*}{ HTN Meds } & Calcium Channel Blockers & 12 & 14 & 0.58 \\
\hline & Beta Blockers & 16 & 16 & 0.93 \\
\hline & Diuretics & 13 & 15 & 0.56 \\
\hline & Angiotensin II receptor antagonist & 12 & 11 & 0.86 \\
\hline & ACE inhibitors & 13 & 14 & 0.75 \\
\hline \multirow[t]{4}{*}{ Diabetes Meds } & insulin & 22 & 16 & 0.21 \\
\hline & biguanides & 19 & 25 & 0.14 \\
\hline & sulfonaurea & 6 & 10 & 0.24 \\
\hline & TZD & 2 & 1 & 0.57 \\
\hline
\end{tabular}

Note: $\mathrm{BMI}=$ body mass index $; \mathrm{HTN}$ Meds= hypertensive medications; $\mathrm{ACE}=$ angiotensin converting enzyme; $\mathrm{TZD}=$ thiazolidinedione 
를

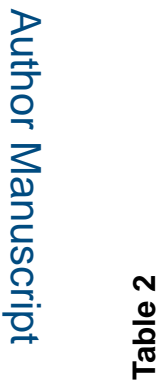

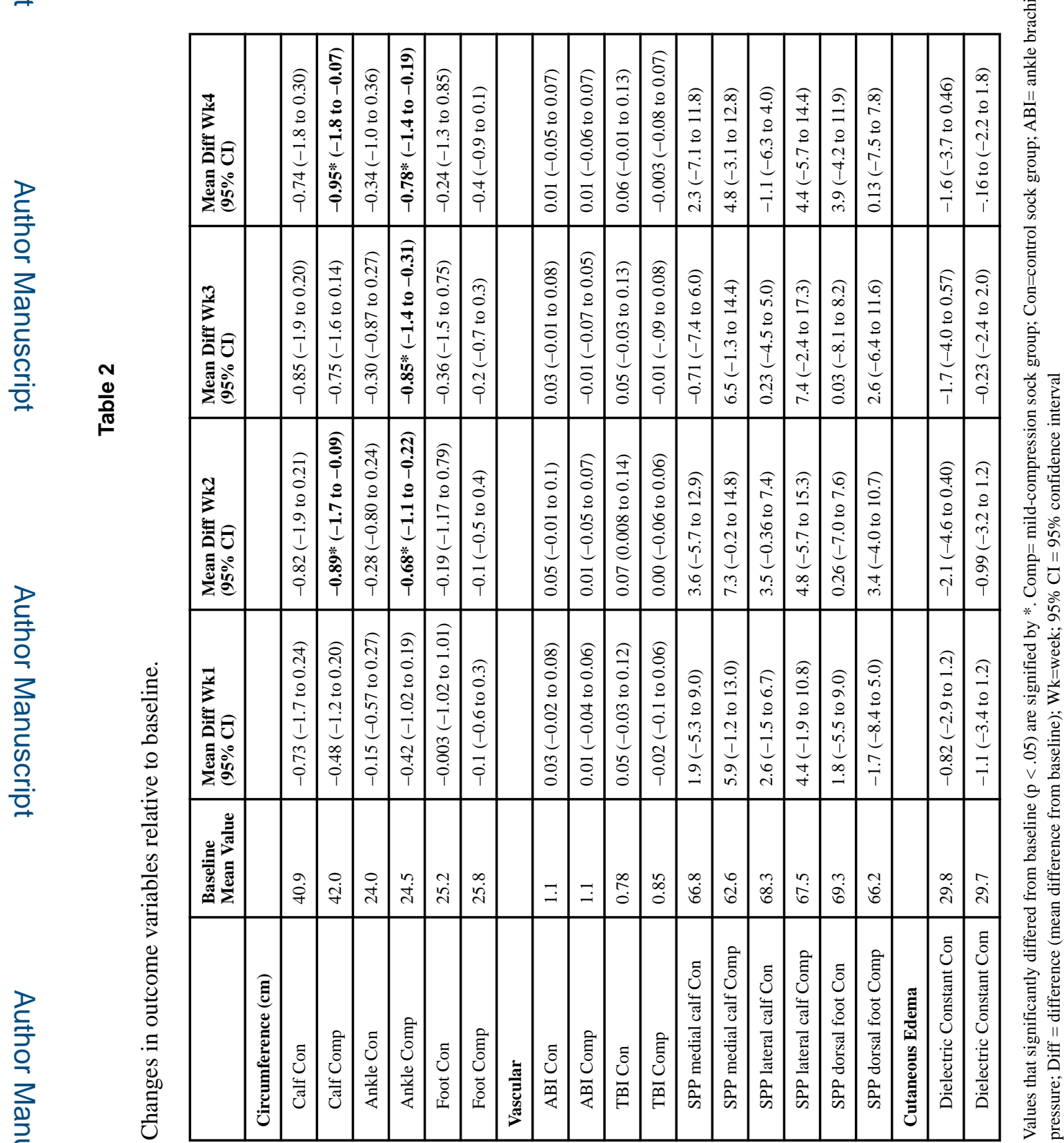

Diabetes Res Clin Pract. Author manuscript; available in PMC 2018 May 01. 


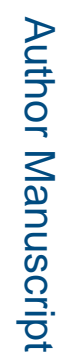

를

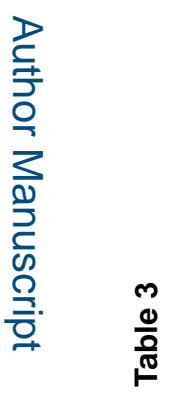

롤

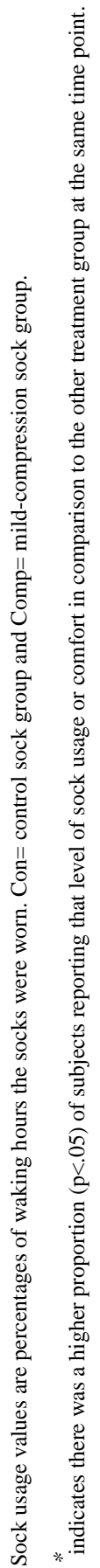

Diabetes Res Clin Pract. Author manuscript; available in PMC 2018 May 01. 
Table 4

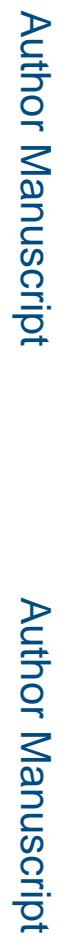

Adverse Events

\begin{tabular}{|l|l|l|}
\hline & Mild Compression & No Compression \\
\hline Adverse Events & $\begin{array}{c}\text { Totals of 4 Adverse Events } \\
\text { 2 AEs were deemed as probably related } \\
\text { to the study device } \\
1 \text { AE was deemed as definitely related to } \\
\text { the study device } \\
1 \text { AE was deemed as possibly related to } \\
\text { the study device }\end{array}$ & $\begin{array}{c}\text { Total of } 6 \text { Adverse Events } \\
4 \text { AEs were deemed as not related to the } \\
\text { study device } \\
1 \text { AE was deemed as possibly related to } \\
\text { the study device } \\
1 \text { AE was not assessed in relation to } \\
\text { study device }\end{array}$ \\
\hline Serious Adverse Events & $\begin{array}{c}\text { Total of 2 Serious Adverse Events } \\
\text { Both SAEs were deemed as not related to } \\
\text { the study device }\end{array}$ & $\begin{array}{c}\text { Total of 1 Serious Adverse Event } \\
\text { That SAE was deemed as not related to } \\
\text { the study device }\end{array}$ \\
\hline
\end{tabular}

